\title{
Effect of Hybrid Nano and Micron Fillers on the Dielectric Properties of Glass Epoxy Composites
}

\author{
Bommegowda K. B., N. M. Renukappa, J. Sundara Rajan
}

\begin{abstract}
Failure of polymer composites in many critical applications has mandated the need for improvements in the electrical, mechanical, and thermal properties using fillers. In this study, different fillers like silicon dioxide, alumina, silicon carbide, molybdenum disulphide, silicon carbide, and graphite have been incorporated into the epoxy matrix which is reinforced with ECR glass woven fabric. The dielectric properties of the hybrid composites namely dielectric constant, dissipation factor, and impedance was determined over a frequency range of $20 \mathrm{~Hz}$ to $10 \mathrm{MHz}$, and at three temperatures namely 25,50 and $75 \pm 2^{\circ} \mathrm{C}$. It is observed that the dielectric constant is in the range of 4 to 11and the composite with molybdenum disulphide shows the highest dielectric constant. The composites show higher differences in the dielectric constant in the low-frequency range, but the differences are reduced at higher frequencies. This fact highlights the role of fillers at lower frequencies and the domination of the reinforced epoxy matrix at higher frequencies. The dielectric constant of hybrid fillers is higher than the composites with micron-sized fillers but are minimally lower than the corresponding values of the nanocomposites. In terms of dissipation factor, no significant differences are observed when the performance of hybrid composites when compared with composites with individual nano or micron-sized fillers. The impedance variations of hybrid composites with frequency are identical and it does not change with temperature and minor differences in magnitude are observed.
\end{abstract}

Index Terms - Epoxy resin, glass woven fabric, dielectric constant, dissipation factor, impedance, nanofillers, micron fillers, hybrid fillers.

\section{INTRODUCTION}

Polymer composites are used in diverse industrial applications because of their multifunctional capabilities. For many industrial applications, polymers are reinforced with glass fibre/fabric for the enhancement of their mechanical properties. The wide-ranging properties of polymers make them ideally suitable for a diverse range of applications in major fields such as aerospace, automobile engineering, construction, communication, electrical systems and energy storage and many other high-end applications. There has been extensive research aimed at enhancement and optimization of the properties of the polymer composites by incorporation of

Bommegowda K. B., Department of Electronics \& Communication Engineering, N.M.A.M. Institute of Technology (Affiliated to the Visvesvaraya Technological University, Belagavi) Nitte, Udupi, Karnataka, India, 9538030875

N. M. Renukappa, Department of Electronics \& Communication Engineering, JSS Science and Technology University, Mysuru, Karnataka, India.

J. Sundara Rajan, Department of Electrical and Electronics Engineering, Siddaganga Institute of Technology, Tumakuru, Karnataka, India. a micron, nano, or a combination of nano-micron hybrid fillers.

The glass fiber reinforcements impart higher mechanical and physical properties to the polymer matrix [1]. The properties of the composites depend heavily on the fiber alignment or the nature of the fabric used [2]. For example, glass fiber reinforced polymer composites have higher impact load tolerance, stiffness, and high specific strength [3]. On the other hand, E-glass fibers are preferred as reinforcement when better electrical insulating properties, low susceptibility to moisture, high mechanical properties, and low cost are the prerequisites [4].

Epoxy composites with well-balanced physical, mechanical, thermal, and electrical properties find application in different fields. They are preferred dielectric materials for use as electrodes in electrochemical sensing applications. Epoxy resins are ideal polymer matrix systems for electronics and electrical systems as well as many other industrial applications [5-6]. To achieve electrically insulating and thermally conducting polymer matrix composites, fillers such as silicon carbide, alumina, and silica have been attempted [7].

In this investigation, different micron and nanofiller particles were incorporated into the epoxy matrix which was reinforced with ECR-glass woven fabric. The effect of fillers on dielectric constant, dissipation factor, and impedance at 25,50 and $75^{\circ} \mathrm{C}$ have been investigated and the results are discussed in this paper. In addition, the surface properties of the hybrid composites namely Arc resistance and Comparative Tracking Index (CTI) has been determined to understand the effect of hybrid fillers. The results of the dielectric and surface properties of the composites are discussed in this paper.

\section{EXPERIMENTAL METHOD}

\section{A. Materials}

The particulars of the resin, hardener, reinforcement, and fillers are furnished in Table 1. The nano fillers of $\mathrm{MoS}_{2}$, graphite and $\mathrm{SiC}$ were prepared from the micron-sized filler particles with indigenous facilities.

\section{B. Method of fabrication}

The hand lay-up method is the simplest of fabrication techniques for the preparation of polymer composites. In this investigation, the wet hand lay-up method was employed. The ECR glass woven roving fabric was manually positioned on a porous teflon sheet. Before mixing, the epoxy resin and hardener were preheated in a vacuum chamber at $65^{\circ} \mathrm{C}$ for $1 \mathrm{~h}$ $30 \mathrm{~min}$ to reduce the viscosity and eliminate trapped air.

The epoxy resin, hardener and the accelerator were then mixed in the ratio of $100: 85: 2.5$ pbw as suggested by the 
Table 1 Details of resin, hardener, reinforcement, and the fillers

\begin{tabular}{|l|l|c|}
\hline \multicolumn{1}{|c|}{ Materials } & Source & $\begin{array}{c}\text { Density } \\
\left(\mathrm{g} / \mathrm{cm}^{3}\right)\end{array}$ \\
\hline ECR glass fabric & Owens Corning, India & 2.66 \\
\hline Epoxy MY740 & Huntsman, USA & 1.16 \\
\hline Hardener & & 1.2 \\
\hline Alumina & \multirow{2}{*}{ Sigma Aldrich, USA } & 2.62 \\
\cline { 1 - 1 } Silica & & 4.0 \\
\cline { 1 - 1 } Graphite & & 2.6 \\
\cline { 1 - 1 } Silicon Carbide & & 3.1 \\
\hline Molybdenum & & 5.06 \\
& & \\
& &
\end{tabular}

manufacturer. The resin and the hardener were initially mixed and the accelerator was then added. To prepare the hybrid filler-based epoxy composites, the required weight percentage of the fillers were mixed with the epoxy-hardener mixture, using a high shear mixer which was operated at 2,000 $\mathrm{rpm}$ for $15 \mathrm{~min}$. The temperature was held at $50^{\circ} \mathrm{C}$ during the mixing process. The resin filler mixture was then infused onto the surface of the glass fabric which was positioned on thin PTFE film. The epoxy impregnated glass fabric was then stacked one above the other with the application of pressure using a hand roller. By this method, the trapped air bubbles and the excess of the epoxy resin were squeezed out. The procedure was repeated until the stacked layers were built up to $3 \mathrm{~mm}$ thickness. A translucent teflon film was used to protect the stack and a $3 \mathrm{~mm}$ spacer was used to ensure uniform thickness of the composite. The entire assembly was then subjected to a pressure of $0.5 \mathrm{MPa}$ in a hydraulic press with bagging. The composites fabricated were pre-conditioned at a temperature of $25 \pm 2^{\circ} \mathrm{C}$ and relative humidity of $50 \pm 5 \%$ for $24 \mathrm{~h}$, before the commencement of the measurements. The composites fabricated were of size $250 \mathrm{~mm} \times 250 \mathrm{~mm} \times 3 \mathrm{~mm}$. The details of composites and

Table 2 Identification of fabricated composites (Figures in parentheses show the weight percentage used)

\begin{tabular}{|c|l|}
\hline Composite & \multicolumn{1}{|c|}{ Description } \\
\hline A & ECR glass fabric (60) + epoxy (40) \\
\hline B & $\begin{array}{l}\text { ECR glass fabric (60) + epoxy (35) + } \\
\text { nano alumina (1) + micron alumina (4) }\end{array}$ \\
\hline C & $\begin{array}{l}\text { ECR glass fabric (60) + epoxy (35) + } \\
\text { nano silica (1) + micron silica (4) }\end{array}$ \\
\hline D & $\begin{array}{l}\text { ECR glass fabric (60) + epoxy (35) + } \\
\text { nano silicon carbide (1) + micron } \\
\text { silicon carbide (4) }\end{array}$ \\
\hline E & $\begin{array}{l}\text { ECR glass fabric (60) + epoxy (35) + } \\
\text { nano molybdenum disulfide (1) + } \\
\text { micron molybdenum disulfide (4) }\end{array}$ \\
\hline F & $\begin{array}{l}\text { ECR glass fabric (60) + epoxy (35) + } \\
\text { nano graphite (1) + micron graphite (4) }\end{array}$ \\
\hline
\end{tabular}

their nomenclature are depicted in Table 2.

C. Method of fabrication

(i) Dielectric Properties
The dielectric properties of the glass epoxy hybrid composites which was measured are the capacitance $(\mathrm{C})$, dissipation factor $(\operatorname{Tan} \delta)$, phase angle $(\theta)$, and Impedance $(Z)$. These parameters were determined by using a high-frequency LCR meter (model 6500P of Wayne Kerr), as per specifications of ASTM D 150-18. A circular specimen having a $50 \mathrm{~mm}$ diameter and a thickness of $3 \mathrm{~mm}$ is positioned between the two-parallel surface of stainless-steel electrodes to measure these parameters. The measuring electrode was guarded, and this helped in increasing the electric field uniformity at the edges. For capacitance (C), dissipation factor $(\operatorname{Tan} \delta)$, phase angle $(\theta)$, and Impedance $(Z)$ the applied voltage level was $1 \pm 0.001 \mathrm{~V}_{\mathrm{rms}}$ and the frequency is swept over a range of 20 to $10 \mathrm{MHz}$. Measurements were carried out at $25^{\circ} \mathrm{C}, 50$ and $75 \pm 2^{\circ} \mathrm{C}$, respectively to understand the effect of temperature on these parameters.

For temperature measurements above the ambient temperature, a compact temperature unit of $0.25 \mathrm{~m}^{2}$ volume was used. The chamber had provisions for precision temperate control, the temperature variations were within $\pm 1^{\circ}$ $\mathrm{C}$ of the set temperatures. The dielectric constant $\left(\varepsilon_{\mathrm{r}}\right)$ were computed from the measured capacitance parameter using the following equation:

The dielectric constant $\left(\varepsilon^{\prime}\right.$ or $\left.\varepsilon_{\mathrm{r}}\right)$ is computed using the following relation:

$$
\varepsilon_{r}=\frac{\mathrm{C} \times \mathrm{t}}{\varepsilon_{0} \times \mathrm{A}}
$$

Where ' $C$ ' represents the capacitance in Farads, ' $\mathrm{t}$ ' is the sample thickness in $\mathrm{cm}, \mathcal{E}_{\mathrm{o}}$ is the permittivity of the free space $\left(8.854 \times 10^{-14} \mathrm{~F} / \mathrm{cm}\right), A$ is the area of the electrode in $\mathrm{cm}^{2}$. The real part $\left(Z^{\prime}\right)$ of the complex impedance is computed using the following relation,

$$
Z^{\prime}=Z \times \operatorname{Cos} \theta
$$

The imaginary part $\left(Z^{\prime \prime}\right)$ of the complex impedance is determined by using the equation:

$$
Z^{\prime \prime}=Z \times \operatorname{Sin} \theta
$$

Here $\mathrm{Z}$ is the impedance in ohms and $\theta$ is the phase angle in degree.

\section{(ii) Arc resistance}

The arc resistance of the composites was measured as per ASTM D495-14 (2014) standard, using a testing machine manufactured by Torino, Italy. The distance between two tungsten electrodes was maintained at $6 \mathrm{~mm}$. The thickness of the specimen used was $3 \mathrm{~mm}$. By applying $12.5 \mathrm{kV}$, the duration and magnitude of the current are increased in steps until the sample failed due to arcing, and surface conduction. The arc resistance is the measure of the length of time in seconds, during which the sample can withstand high voltage/low current arc. An average of 10 measurements is reported as the arc resistance of the composite.

Using the same test set-up, the ability of the material to regain insulation after the arc is extinguished was determined by the application of an AC signal from the apparatus. The surface flashover voltage before and after the extinction of the arc gives a measure of the ability of the composite to regain insulation once the surface arc is put off.

(iii) Comparative tracking index 
The Comparative Tracking Index (CTI) was performed as per IEC 60112:2020 using an automatic tracking index analyzer. In this study, two platinum electrodes are placed on the surface of the specimen at a distance of $4 \mathrm{~mm}$ from each other and an AC voltage of $600 \mathrm{~V}$ is applied across the electrodes. A sample of $3 \mathrm{~mm}$ thickness was used. Ammonium chloride $\left(\mathrm{NH}_{4} \mathrm{Cl}\right)$ solution of $0.1 \%$ concentration having a volume resistivity of $380 \Omega-\mathrm{cm}$ was used as the contaminant with a drop size of $20 \pm 2 \mathrm{~mm}^{3}$ falling in the inter-electrode area every $30 \mathrm{~s}$. The numerical value of the voltage at which 50 drops of the electrolyte are withstood by the surface is reported as comparative tracking index of the composite. An average of 10 measurements is reported as the comparative tracking index of the composite.

\section{RESULTS AND DISCUSSIONS}

\section{A. Variations in dielectric constant}

Capacitance measurements were carried out in the $20 \mathrm{~Hz}$ to $10 \mathrm{MHz}$ frequency range at 25,50 , and $75 \pm 2^{\circ} \mathrm{C}$ respectively, and the variations in the dielectric constants $\left(\varepsilon_{\mathrm{r}}\right)$ are addressed with different fillers.

\section{(i) Variations in dielectric constant at $25^{\circ} \mathrm{C}$}

The changes in the dielectric constant ' $\varepsilon_{\mathrm{r}}$ ' of the composites at room temperature as a function of frequency is in Figure 1. The $\varepsilon_{\mathrm{r}}$ of base epoxy composite with ECR glass woven fabric (composite $\mathrm{A}$ ) is 4.5 and shows only marginal variation with frequency. This value is the combined influence of the dielectric constant of epoxy which varies from 4 to 4.25 and that of ECR glass fiber which varies from 7 to 9 .

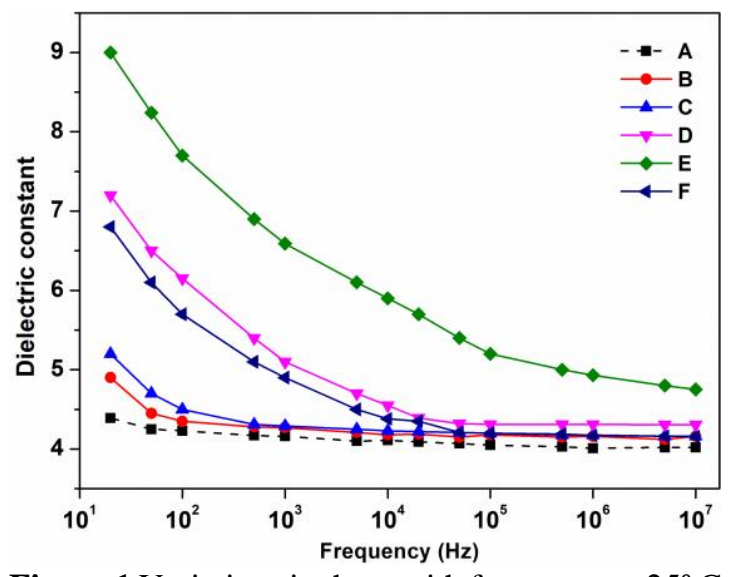

Figure 1 Variations in the $\varepsilon_{\mathrm{r}}$ with frequency at $25^{\circ} \mathrm{C}$

In composite $\mathrm{B}$, due to alumina filler, the dielectric constant increases at $20 \mathrm{~Hz}$ to 5.25 and gradually decreases with frequency and the value is close to that of the epoxy. In case of composite $\mathrm{C}$, the use of silica filler reveals an increase in the dielectric constant to at $20 \mathrm{~Hz}$ increases to 5 and reduces to the level of the base composite at $100 \mathrm{~Hz}$ and thereafter there is no difference between the dielectric constant of composite $\mathrm{C}$ and $\mathrm{A}$.

A considerable increase in the dielectric constant is observed in case of composite D due to the incorporation of $\mathrm{SiC}$ filler. The dielectric constant increases to 7.4 at $20 \mathrm{~Hz}$ and thereafter a reduction is observed with an increase in frequency. The difference in the dielectric constant of composite $\mathrm{D}$ and $\mathrm{A}$ is observed to be around $13 \%$ at $5 \mathrm{kHz}$ and reduces further with an increase in frequency. The dielectric constant of composite $\mathrm{E}$ is observed to be 9 which is nearly twice the value of composite A at $20 \mathrm{~Hz}$. But with an increase in frequency, the differences are reduced to about 16 $\%$. Thus, the increase in the dielectric constant is highest at 20 $\mathrm{Hz}$ for all the composites in comparison to the value of composite $\mathrm{A}$, but the differences are very much reduced with an increase in frequency. The variations in the dielectric constant of composite $\mathrm{F}$ (graphite filler) closely follows that of composite-D. At $20 \mathrm{~Hz}$, the dielectric constant is 6.8, which is about $45 \%$ higher than the dielectric of composite A at 20 $\mathrm{Hz}$ and the value reduces by $20 \%$ below the corresponding value of composite-A at a higher frequency range of 1 to 10 $\mathrm{MHz}$. Thus, there is significant influence at the lowest frequency of $20 \mathrm{~Hz}$ due to the incorporation of fillers mainly due to the semiconducting nature of the fillers. However, in the $\mathrm{MHz}$ range of frequency, the difference between the base material and the composite with the semi-conducting fillers is very much reduced, mainly due to the rapid changes in the electric field and the inability of the dipoles to orient themselves under rapidly changing electric field.

The increase in the dielectric constant of composite B with respect to the variations in composite-A shows a maximum increase of $11.6 \%$ at $20 \mathrm{~Hz}$, which gradually reduces to less than $1 \%$ around $5 \mathrm{kHz}$. In case of composite $\mathrm{C}$, the increase in dielectric constant increases by $18.45 \%$ at $20 \mathrm{~Hz}$ and it reduces to $1.2 \%$ at $10 \mathrm{MHz}$. In composite $\mathrm{D}$, a $64 \%$ increase in the dielectric constant is observed at $20 \mathrm{~Hz}$ and it reduces to $1.2 \%$ at $10 \mathrm{MHz}$ and in $\mathrm{E}$ the corresponding increase at $20 \mathrm{~Hz}$ is $105 \%$, which is the highest and reduces to $16.7 \%$ at 10 $\mathrm{MHz}$. The increase in case of composite $\mathrm{F}$ at $20 \mathrm{~Hz}$ is $55 \%$ and it reduces to $1.2 \%$ at $10 \mathrm{MHz}$. Thus, the highest increase in the dielectric constant is seen in case of composite $\mathrm{E}$ due to the incorporation of $\mathrm{MoS}_{2}$ filler. It is also significant that even at $10 \mathrm{MHz}$, the difference in the $\varepsilon_{\mathrm{r}}$ value is $16.71 \%$, whereas in all other composites, the difference in the $\varepsilon_{\mathrm{r}}$ values of the composites with filler and composite $\mathrm{A}$ are very minimal. Thus, $\mathrm{MoS}_{2}$ filler shows unique characteristics of retaining a much higher dielectric constant than other hybrid composites, throughout the range of frequency investigated.

\section{(ii) Variations in dielectric constant at $50^{\circ} \mathrm{C}$}

The dielectric constant of the glass epoxy hybrid composites at $50^{\circ} \mathrm{C}$ as a function of frequency is depicted in Figure 2. The composite A shows an increase in the dielectric constant from 4.39 to 4.8 at $20 \mathrm{~Hz}$ due to an increase in temperature from 25 to $50^{\circ} \mathrm{C}$. The dielectric constant of composite B increases to 4.9 from 5.5, due to an increase in temperature from 25 to $50^{\circ} \mathrm{C}$. In case of composite $\mathrm{C}$, the increase is from 5.2 to 5.72 at $20 \mathrm{~Hz}$, and the change in composite D is from 7.2 to 7.92 . The corresponding changes in composite $\mathrm{E}$ it is from 9 to 10.4 and in $\mathrm{F}$ it is from 6.8 to 7.47 respectively. Thus, the composites with fillers show a relatively higher increase in the dielectric constant with an increase in temperature.

The composite A shows minimal near frequency invariance at $50^{\circ} \mathrm{C}$ and in this respect the results of 25 and $50^{\circ} \mathrm{C}$ are identical. However, in all other composites with hybrid fillers relatively more reduction in the dielectric constant is observed from $20 \mathrm{~Hz}$ to $1 \mathrm{kHz}$ and beyond this frequency range, the variation in the dielectric constant is not so significant. 


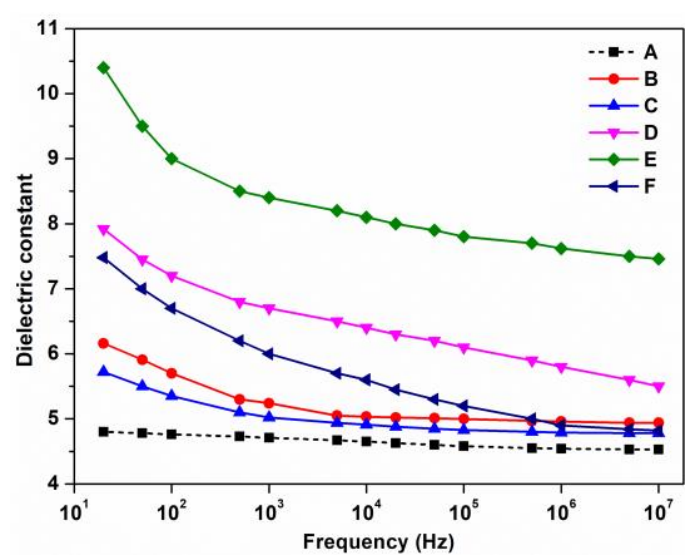

Figure 2 Variations in the $\varepsilon_{\mathrm{r}}$ with frequency at $50^{\circ} \mathrm{C}$

At $20 \mathrm{~Hz}$, the values of the dielectric constant of the hybrid fillers in comparison to the composite A shows that $114.6 \%$ increase results in composite B due to alumina filler, $19.2 \%$ increase results from the incorporation of silica filler, $65 \%$ increase results from Sic filler, $117 \%$ increase results from $\mathrm{MoS}_{2}$ filler and $56 \%$ increase results from the use of graphite filler. Thus, composite E, constantly shows a much higher dielectric constant which is $115 \%$ higher than that of composite A, both at 25 and $50^{\circ} \mathrm{C}$. In case of composite D and $\mathrm{F}$, the increase is 65 and $56 \%$ at $50^{\circ} \mathrm{C}$ which is identical to the values observed at $25^{\circ} \mathrm{C}$. Thus, the three hybrid fillers namely $\mathrm{SiC}, \mathrm{MoS}_{2}$ and graphite exhibit a much higher dielectric constant at the lowest frequency of $20 \mathrm{~Hz}$. With an increase in frequency to $10 \mathrm{MHz}$, the dielectric constant of the composites shows an increase of $10 \%$ in composite B, $5.5 \%$ in composite $\mathrm{C}, 21.5 \%$ in composite $\mathrm{D}, 65.6 \%$ in composite $\mathrm{E}$ and $7 \%$ in composite F. Thus, composite $\mathrm{E}$ has a much higher dielectric constant than all other composites, even at $10 \mathrm{MHz}$. It is important to note that at $50^{\circ} \mathrm{C}$, all the composites are much higher than the corresponding values at $25^{\circ} \mathrm{C}$. Thus, the effect of temperature is seen in terms of a higher dielectric constant at the highest frequency, and in this aspect, the effect of temperature appears to be very dominant.

\section{(iii) Variations in dielectric constant at $75^{\circ} \mathrm{C}$}

The distinctions in the $\varepsilon_{\mathrm{r}}$ of the glass epoxy composites at $75^{\circ} \mathrm{C}$ is depicted in Figure 3. With an increase in temperature from 50 to $75^{\circ} \mathrm{C}$, composite A shows a minimal rise in $\varepsilon_{\mathrm{r}}$ to 5.2 from 4.8 at $50^{\circ} \mathrm{C}$. The dielectric constant of composite $\mathrm{B}$ increases to 6.3 at $20 \mathrm{~Hz}$ as compared to 5.5 at $50^{\circ} \mathrm{C}$ and the dielectric constant of composite $\mathrm{C}$ is observed to increases from 5.72 at $50^{\circ} \mathrm{C} 6.27$ at $75^{\circ} \mathrm{C}$. The dielectric constant of composite $\mathrm{D}$ increases to 7.92 at $20 \mathrm{~Hz}$ and $50^{\circ} \mathrm{C}$ to 8.72 at $75^{\circ} \mathrm{C}$. The $\varepsilon_{\mathrm{r}}$ of composite $\mathrm{E}$ increases from 7.48 to 10.40 . The increase in the dielectric constant of the composites with fillers are $14.6 \%$ in B, $18.8 \%$ in C, $65.2 \%$ in D, $101.2 \%$ in $\mathrm{E}$ and $53.2 \%$ in case of composite $\mathrm{F}$. The increase in the dielectric constant of the composites with fillers in comparison to the dielectric constant of the epoxy composite is identical to the results observed at $50^{\circ} \mathrm{C}$. Thus, the effect of temperature of 50 and $75^{\circ} \mathrm{C}$ result is identical margin of increase in the dielectric constant of the composites with fillers at $20 \mathrm{~Hz}$.

The dielectric constant of composite A reduces to 5.03 at $10 \mathrm{MHz}, 5.2$ in composite B, 5.58 in C, 6.6 in D, 8.4 in F and

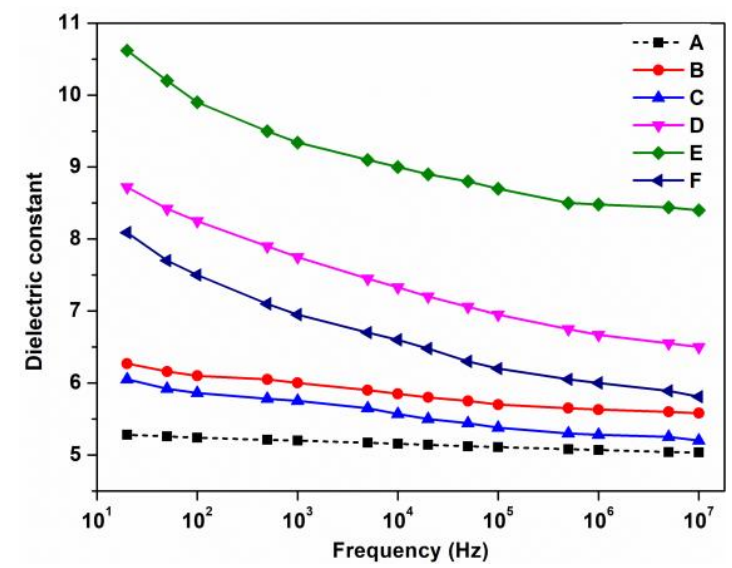

Figure 3 Variations in the $\varepsilon_{\mathrm{r}}$ with frequency at $75^{\circ} \mathrm{C}$

5.81 in composite F. The increase in dielectric constant at 10 $\mathrm{MHz}$ in comparison to the value of composite $\mathrm{A}$ is observed to be higher by $3.2 \%$ in B, $10.8 \%$ higher in C, $29 \%$ higher in $\mathrm{D}, 66.8 \%$ higher in $\mathrm{E}$ and $15.4 \%$ higher in composite $\mathrm{F}$. Thus, composite E shows a much larger dielectric constant in comparison to all other composites. Thus, the effect of $\mathrm{MoS}_{2}$ filler is more dominant over the entire range of frequency as compared to all other composites with hybrid fillers. All the composites show sensitivity towards temperature and there is an increase in the dielectric constant due to a rise in temperature. The highest increase in dielectric constant is seen in $\mathrm{MoS}_{2}$, which is seen over the entire range of frequency, though in decreasing order.

The frequency of the applied voltage will impact the polarization mechanism [9]. From Figures 1, 2 and 3, it can be seen that the glass-epoxy composites do not show a drastic reduction of $\varepsilon_{\mathrm{r}}$ with the frequency. In a conventional epoxy composite, the number of dipoles which can reorient with the ability to align under the action of the external electric field decides the dielectric constant [10]. In case of epoxy chains, at lower frequencies, the majority of the free dipolar functional groups tend to align. Thus, in the lower frequency range epoxy composites have higher $\varepsilon_{\mathrm{r}}$ values. The orientation of dipoles of the larger dipolar groups is difficult when the frequency is increased [11]. Hence with an increase in the frequency, the effect of the dipolar groups on $\varepsilon_{\mathrm{r}}$ is reduced.

The influence of hybrid fillers on the dielectric constant of the composites when compared with that of the composites with nano and micron-sized fillers, shows some variations. The maximum difference in the dielectric constant was within $\pm 5 \%$, with the increase being observed over the values of the composites with micron-sized filler and decrease is with respect to the composites with nanofillers. It is important to note that the differences are not incredibly significant, since such differences can occur due to differences involved during fabrication, experimental errors, and also environmental factors. The glass fabric content used is highly divergent and hence differences are expected. Further, for the hybrid fillers to impact the dielectric constant in a significant way, a much higher weight percentage of the fillers would be required More such studies involving higher wt. \% of the fillers are required to establish the effect of the fillers on the dielectric constant.

\section{B. Variations in dissipation factor}

To understand the effect of fillers on dissipation factor (Tan $\delta$ ), the measurements were carried out at 25,50 , and $75^{\circ}$ 
$\mathrm{C}$ in the $20 \mathrm{~Hz}-10 \mathrm{MHz}$ frequency range and the findings are discussed.

\section{(i) Variations in dissipation factor at $25^{\circ} \mathrm{C}$}

The changes in the Tan $\delta$ of the composites as a function of frequency at $25^{\circ} \mathrm{C}$ is depicted in Figure 4. The Tan $\delta$ of all the composites show minimal variations in the frequency range of $20 \mathrm{~Hz}$ to $10 \mathrm{kHz}$ at $25^{\circ} \mathrm{C}$. In the frequency range of $20 \mathrm{~Hz}$ to $100 \mathrm{kHz}$, there are differences in the Tan $\delta$ of the composites. The Tan $\delta$ of composite $\mathrm{A}$ and $\mathrm{E}$ show identical variations, with the value varying from 0.025 and increasing only marginally up to $100 \mathrm{kHz}$. The Tan $\delta$ of composite A increases 0.025 to 0.038 at $10 \mathrm{MHz}$. In case of composite E, it increases to 0.1 at $10 \mathrm{MHz}$. Composite B and D, the Tan $\delta$ remains nearly invariant with frequency from $20 \mathrm{~Hz}$ to 100 $\mathrm{kHz}$ at 0.047 and increases more rapidly to 0.08 at $10 \mathrm{MHz}$. Though composite D shows a similar trend, beyond $100 \mathrm{kHz}$, the values of Tan $\delta$ are higher and it reaches 0.13 at $10 \mathrm{MHz}$.

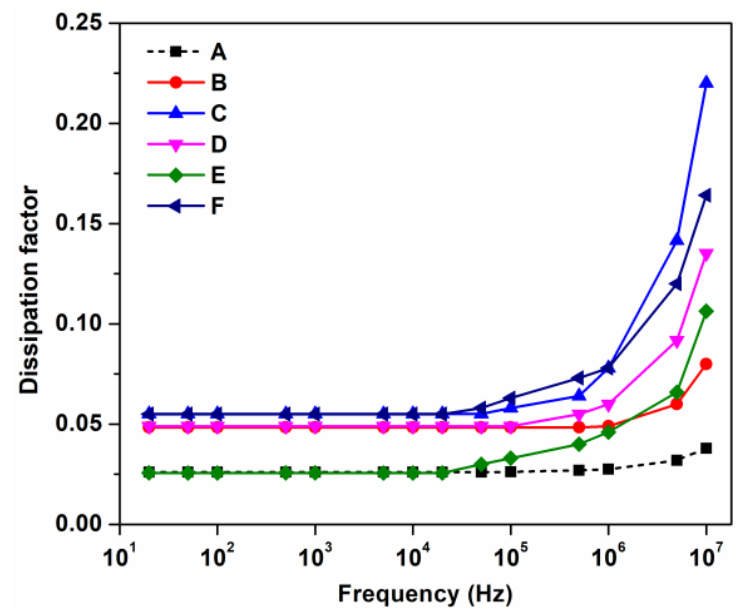

Figure 4 Variations in Tan $\delta$ with frequency at $25^{\circ} \mathrm{C}$

The Tan $\delta$ values of composites $\mathrm{C}$ and $\mathrm{F}$ are relatively higher at 0.055 and it remains invariant up to $100 \mathrm{kHz}$. However, at $10 \mathrm{MHz}$, the corresponding Tan $\delta$ value of $\mathrm{C}$ is 0.22 and that of composite $F$ is 0.16 . Thus, the Tan $\delta$ values of the composites with fillers show divergent trends beyond 100 $\mathrm{kHz}$ but are frequency invariant in the low-frequency range. Though the $\sigma_{\mathrm{ac}}$ due to the filler is the dominating factor determining the Tan $\delta$ [12], perhaps the low electrical conductivity of ECR glass fabric overrides this effect and a near invariance of dissipation factor is observed in the low-frequency range. Similar results with Tan $\delta$ are observed for $20 \mathrm{~Hz}$ to $10 \mathrm{kHz}$ in case of alumina fillers in epoxy by some authors [13] for wt. $\%$ of $\mathrm{Al}_{2} \mathrm{O}_{3}$ ranging from 1 to $7 \mathrm{wt}$. $\%$.

\section{(ii) Variations in dissipation factor at $50^{\circ} \mathrm{C}$}

The changes in the dissipation factor of the composites with frequency at $50^{\circ} \mathrm{C}$ is shown in Figure 5 . The trends in the variations of Tan $\delta$ with frequency follow the trends observed at $25^{\circ} \mathrm{C}$, but for the marginal increase of less than $5 \%$ in the magnitude of Tan $\delta$. The Tan $\delta$ of composite $\mathrm{A}$ is around 0.028 and remains invariant up to $100 \mathrm{kHz}$ and then increases to 0.08 at $10 \mathrm{MHz}$. Composite B shows an increase in Tan $\delta$ to 0.055 which remains invariant up to $100 \mathrm{kHz}$ and the Tan $\delta$ increases to 0.1. In Composite $\mathrm{E}$ variations of Tan $\delta$ with frequency are similar to that of composite $\mathrm{B}$, and the Tan $\delta$ of the invariant frequency region is 0.0 .063 from $20 \mathrm{~Hz}$ to 100 $\mathrm{kHz}$ and then increases to 0.18 at $10 \mathrm{MHz}$. Composite D shows constant Tan $\delta$ of 0.056 from $20 \mathrm{~Hz}$ to $100 \mathrm{kHz}$ which increases to 0.13 at $10 \mathrm{MHz}$. Similarly, in composite E and F, the corresponding values of Tan $\delta$ are 0.032 and 0.06 in the 20 $\mathrm{Hz}$ to $100 \mathrm{kHz}$ range and 0.123 and 0.165 at $10 \mathrm{MHz}$.

Composites B, C, D, and F show relatively higher Tan $\delta$ in the frequency range of $20 \mathrm{~Hz}$ to $100 \mathrm{kHz}$ and a much larger increase at $10 \mathrm{MHz}$ is seen in all the composites, irrespective of the nature of the hybrid filler used. It is well recognized that the Tan $\delta$ of the composites is inversely proportional to $\varepsilon_{\mathrm{r}}$ and applied frequency, whereas it is directly proportional to $\sigma_{\mathrm{ac}}$ of the composites according to the equation:

$$
\sigma_{a c}=2 \pi f \varepsilon_{r} \varepsilon_{0} \operatorname{Tan} \delta
$$

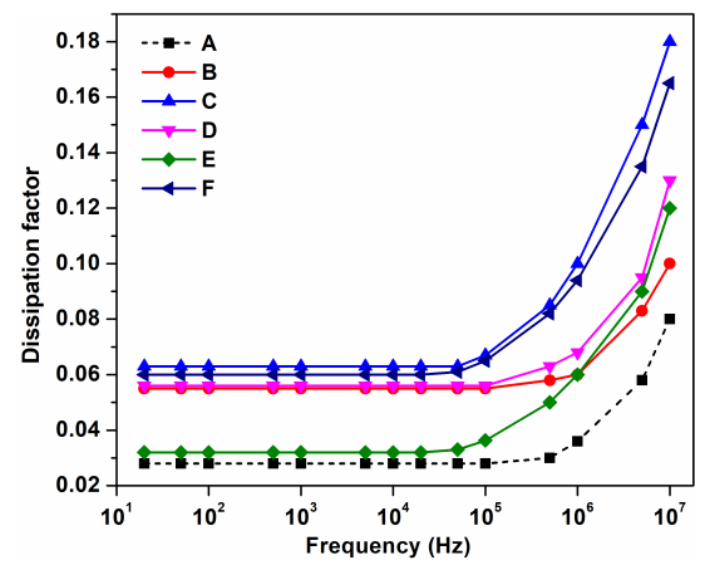

Figure 5 Variations in Tan $\delta$ with frequency at $50^{\circ} \mathrm{C}$

Further, it is also important to consider the nature of the hybrid fillers used. Fillers like $\mathrm{MoS}_{2}, \mathrm{SiC}$ and graphite are all semiconducting in nature, whereas silica and alumina are relatively less conducting. However, at a temperature of $50^{\circ}$ $\mathrm{C}$, there is an increase in Tan $\delta$ of the composites, more prominently in composites $\mathrm{B}, \mathrm{C}, \mathrm{D}$ and $\mathrm{F}$, which is due to alumina, silica, $\mathrm{SiC}$ and graphite. In the low-frequency region, $\mathrm{MoS}_{2}$ shows a marginal increase in Tan $\delta$ over the value of composite A, but with an increase in frequency, especially at a higher frequency, the differences become more prominent.

\section{(iii) Variations in dissipation factor at $75^{\circ} \mathrm{C}$}

The dissipation factor of the hybrid composites as a function of frequency at $75^{\circ} \mathrm{C}$ is depicted in Figure 6. With an increase in the temperature, there is a further increase in the Tan $\delta$ values of the composites. The Tan $\delta$ of composite A remains at 0.31 from $20 \mathrm{~Hz}$ to $100 \mathrm{kHz}$ and then increases and reached 0.1 at $10 \mathrm{MHz}$. In case of composite $\mathrm{B}$, Tan $\delta$ is observed to be 0.06 from $20 \mathrm{~Hz}$ to $100 \mathrm{kHz}$ and then it increases to 0.11 at $10 \mathrm{MHz}$. The corresponding variations in the frequency invariant region of composite $\mathrm{C}$ is 0.069 and the corresponding value at $10 \mathrm{MHz}$ is 0.198 . In case of composite $\mathrm{D}$, the values are 0.062 and 0.131 , and in $\mathrm{E}$ it is 0.04 and 0.14 , respectively. The Tan $\delta$ further increases to 0.066 in composite $\mathrm{F}$ from $20 \mathrm{~Hz}$ to $100 \mathrm{kHz}$ and reaches a high value of 0.17 at $10 \mathrm{MHz}$. Thus, higher Tan $\delta$ values are observed in composites with hybrid fillers. 


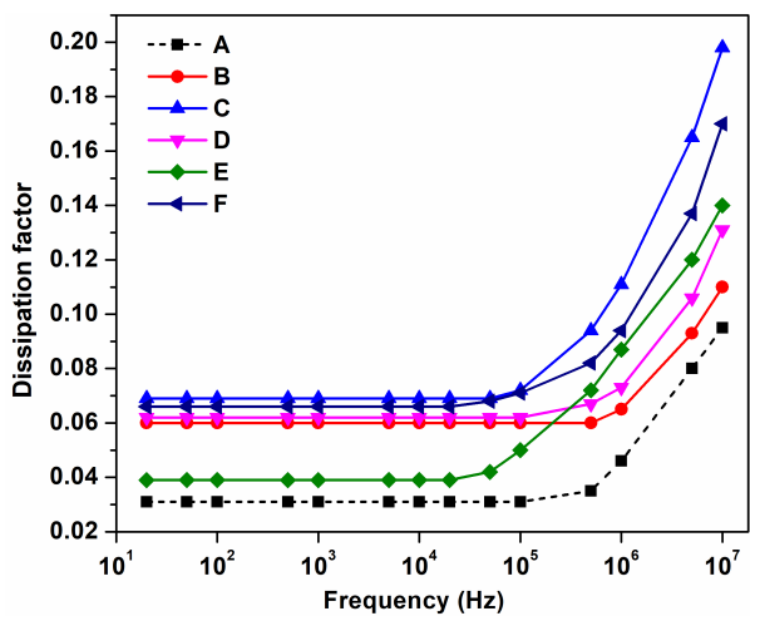

Figure 6 Variations in Tan $\delta$ of the composites with frequency at $75^{\circ} \mathrm{C}$

In polymer composites, the movement of charge carriers in the polymer matrix is obstructed by the large area between the interfaces of the filler and the polymer chains, which can result in a decrease in electrical conductivity and Tan $\delta$. From Figures 4,5 , and 6 it is observed that with an increase in frequency the Tan $\delta$ appears to be invariant, though in reality there is a minimal variation in the lower frequency region. This tends to lower the value of electrical conductivity due to the polymer chain entanglements within the large area of the epoxy-filler interfaces.

The epoxy composites with hybrid fillers show an increase in the Tan $\delta$ values over a narrow range with an increase in temperature. This trend is ascribed to the thermal motion of small side groups of polymers. Further, due to the thermally stimulated ions, a minimal increase in the electrical conductivity would result and hence there is an increase in the Tan $\delta$ values.

\section{Variations in the impedance of hybrid composites}

Impedance $(Z)$ is a complex parameter consisting of the real part $\left(Z^{\prime}\right)$ which is due to the resistance and the imaginary part $\left(Z^{\prime \prime}\right)$ which is due to reactance (the loss factor). In fact, $Z$ $=Z^{\prime}+j Z^{\prime \prime}$ where $\mathrm{j}=-1$. Insulating materials are characterized by a significant decrease in $Z^{\prime}$ as a function of frequency. Further, virgin epoxy and epoxy nanocomposites in which the filler concentrations are well below the electrical percolation threshold would perform in a similar way. If the impedance variations of the composites with frequency are identical and do not change with temperature but show minor differences in magnitude are observed, then it points towards the fact that the electrical conductivity does not significantly vary with the incorporation of hybrid fillers, so that the phase transition from insulating to conducting would not be possible. In case of highly conducting composites, at critical frequency $f_{c}$, a transition due to the presence of nano or micron fillers would arise from the resistive to capacitive nature of the composite. It is also evident that the critical frequency $f_{c}$ will increase when the filler concentration is higher. Though $\mathrm{MoS}_{2}$, graphite and $\mathrm{SiC}$ are semiconducting, the wt. \% of the hybrid fillers used are below the percolation levels of electrical conductivity. The critical frequency $f_{c}$ of the composites is observed at $5 \mathrm{kHz}$, irrespective of the hybrid fillers and this fact emphasizes the dominating role of the epoxy matrix with the glass reinforcement.

The variation in the impedance as a function of frequency at 25,50 and $75 \pm 2^{\circ} \mathrm{C}$ of the composites with different fillers are shown in Figures 7, 8, and 9, respectively. The impedance of the hybrid composites is significantly reduced with an increase in frequency owing to an increase in interfacial polarization [11]. Composite $\mathrm{C}$ with silica filler shows the highest impedance at $25^{\circ} \mathrm{C}$, followed by epoxy. The differences in the impedance of the other composites in the low-frequency range of $20 \mathrm{~Hz}$ to $1 \mathrm{kHz}$ is not significant.

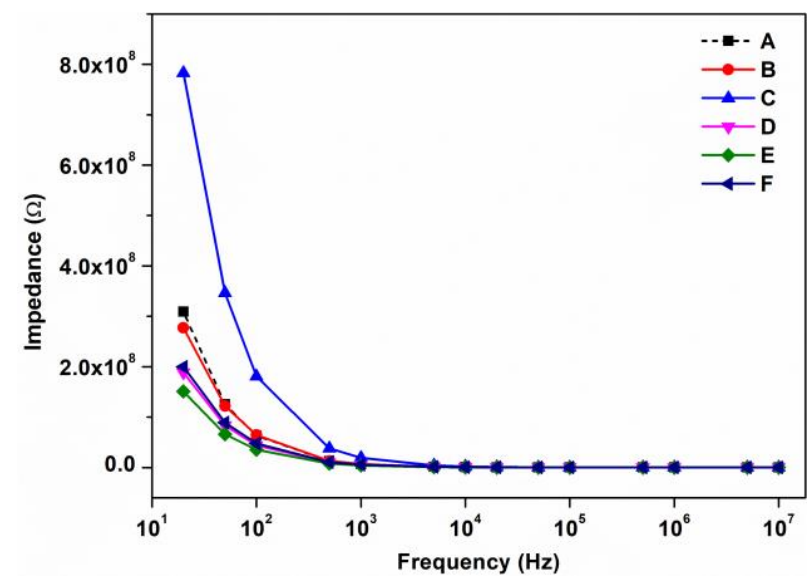

Figure 7 Variations in impedance at $25^{\circ} \mathrm{C}$

At $50^{\circ} \mathrm{C}$, the impedance of the composites A, B and C are higher than the impedance of other composites in the low-frequency range of $20 \mathrm{~Hz}$ to $1 \mathrm{kHz}$. Similar results are observed at $75^{\circ} \mathrm{C}$. Since the capacitance is much higher with fillers like $\mathrm{MoS}_{2}, \mathrm{SiC}$ and graphite, the increasing impedance is relatively higher in case of composite $\mathrm{A}, \mathrm{B}$ and $\mathrm{C}$ and very much reduced in composited $\mathrm{D}, \mathrm{E}$ and $\mathrm{F}$. The frequency response of the impedance of the composites can be divided into two different regions. At low frequencies, the impedance is dependent on the frequency, which implies that the ohmic resistance plays a significant role, while the capacitive effects are reduced. With the increase in frequency, the magnitude of the impedance decreases, which suggests that the impedance follows the typical characteristics of a capacitor.

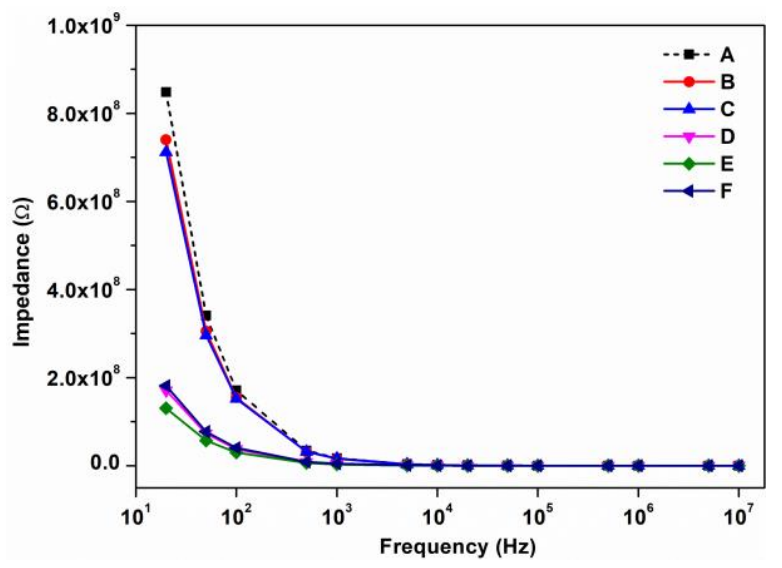

Figure 8 Variations in impedance at $50^{\circ} \mathrm{C}$ 


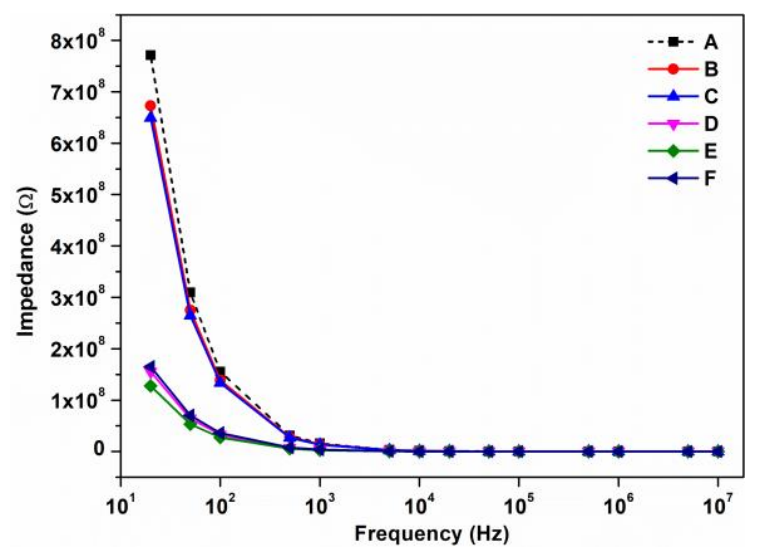

Figure 9 Variations in impedance at $75^{\circ} \mathrm{C}$

There is also a possibility of a reduction in impedance of the hybrid composites due to the increase in the $\mathrm{AC}$ conductivity of the composites in the low-frequency band. The overlapping of the impedance values of the composites in the region of $10 \mathrm{kHz}$ to $10 \mathrm{MHz}$ indicates that (a) impedance at high frequency is independent of the fillers (b) space charge effects and (c) the barrier properties of the composites which are likely to be reduced. The variations in electrical properties of the composites namely the conductivity, impedance, and dielectric constant are attributed to the generation of the internal electric field due to the space charge polarization [12]. At $25^{\circ} \mathrm{C}$, the impedance of composite $\mathrm{C}$ is the highest in the low-frequency region and but at 50 and $75^{\circ} \mathrm{C}$, the impedance is higher in composites $\mathrm{A}, \mathrm{B}$ and $\mathrm{C}$, though the differences in impedance values are not incredibly significant.

\section{Nyquist plot of Impedance}

In hybrid composites, the interfacial area and free volume inside the matrix are distinct since the size of the fillers is different. It is the natural tendency of the epoxy matrix [14] to suppress the interfacial polarization. To understand this aspect, the variations in the Nyquist plot of the impedance at three temperatures are shown in Figures 10, 11, and 12 at 25, 50 and $75^{\circ} \mathrm{C}$, respectively. Two distinct polarization mechanisms are evident from the nature of the plots. The arc of the semicircle shows minimal deviations due to the incorporation of hybrid fillers. If a single relaxation process were to exist, then only the semicircle would exist. The existence of the linear portion of the low-frequency region confirms the presence of two distinct polarization mechanisms and the semi-circular response of the Nyquist plot is attributed to the dominating effect of the epoxy matrix [14].

From the Nyquist plot, it is also evident that the effect of fillers on the interfacial polarization is not incredibly significant. At $25^{\circ} \mathrm{C}$, though there are minimal changes, the composites B, E, and F exhibit a decrease of slopes of the linear portion than other composites. But at 50 and $75^{\circ} \mathrm{C}$, the slope of the linear portion of the plot of all the composites is below that of composite A. The linear portion of the Nyquist plot is due to the dc conductivity component. Thus, the influence of fillers is not observed to be very dominant, and the high-frequency response is almost identical. The minimal changes in the slope of the tail portion of the Cole-Cole plot indicate that some differences come into the picture due to the fillers in the low-frequency region.
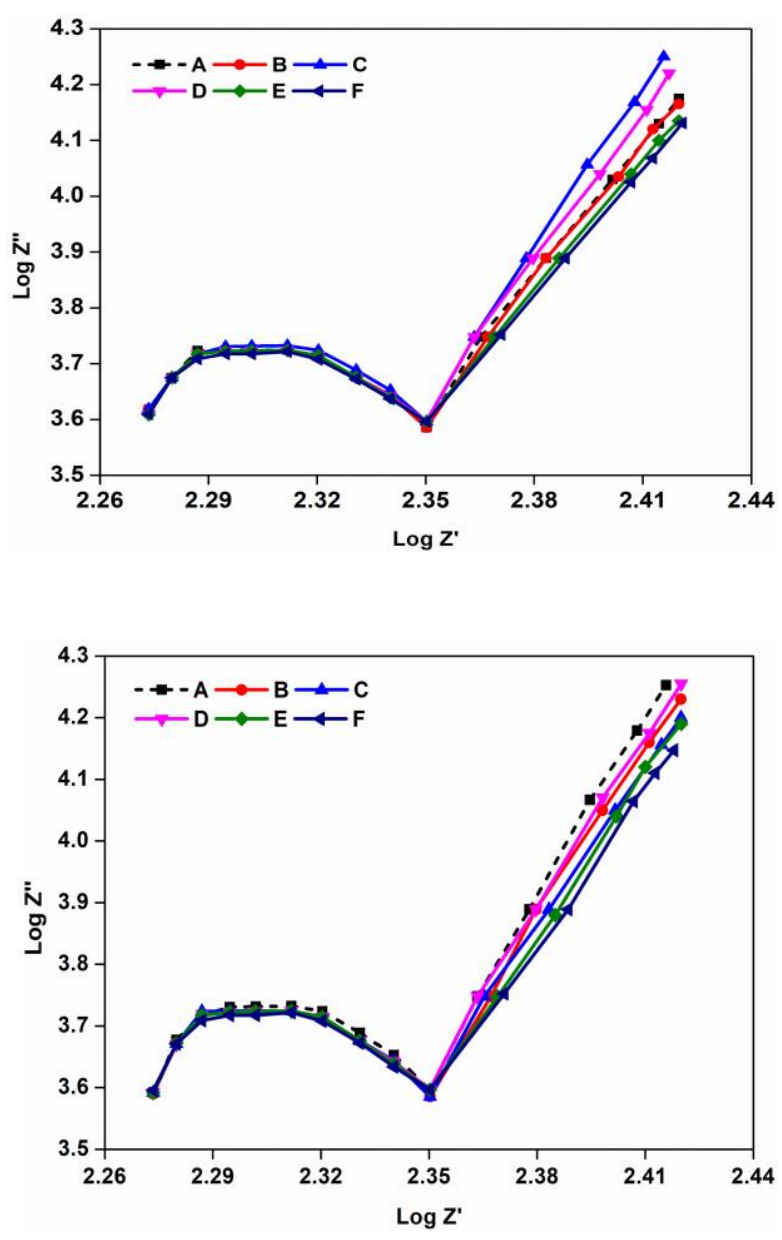

Figure 11 Variations in $\log Z^{\prime}$ v/s $\log Z^{\prime \prime}$ at $50^{\circ} \mathrm{C}$

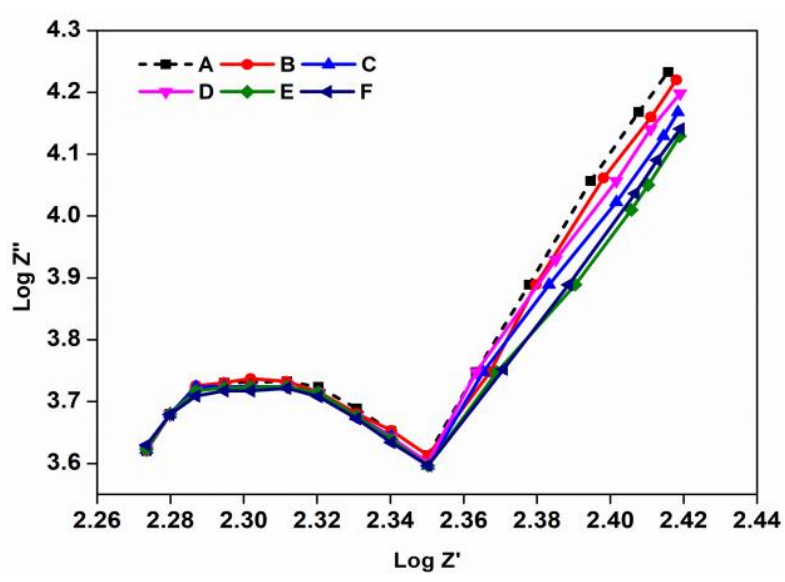

Figure 12 Variations in $\log Z^{\prime} v / s \log Z^{\prime \prime}$ at $75^{\circ} \mathrm{C}$

\section{E. Surface properties of the composites}

Some of the important surface properties of the composites, which characterized the nature of the surface and its capability to surface arcing and presence of high voltage low current arc are discussed in this section.

\section{(i) Comparative tracking index (CTI)}

The CTI of the composites is listed in Table 3. The composite-A has a CTI of 600, implying that it can withstand 50 drops of $\mathrm{NH}_{4} \mathrm{Cl}$ solution of conductivity of $380 \Omega-\mathrm{cm}$, without forming a conductive path which can support $1 \mathrm{~A}$ of current for more than $2 \mathrm{~s}$. The composites have shown good performance which is indicative of the resistance of the composites to mild moist conditions that normally prevail under indoor conditions. The values of CTI confirm that the epoxy has a major role in maintaining in offering a resistance 
to surface tracking. Though the composites show leakage currents of the order of 1A momentarily with fillers like SiC, $\mathrm{MoS}_{2}$, and graphite, the high thermal conductivity helps in preventing surface damage due to pyrolysis and hence the recovery of the materials is exceptional. Thus, even with semiconducting fillers, which are also thermally particularly good conductors, the composites can dissipate heat more efficiently and thus the CTI does not deteriorate.

Table 3 Comparative tracking index of hybrid composites

\begin{tabular}{|c|c|}
\hline Composite & CTI \\
\hline A & 600 \\
\hline B & 600 \\
\hline C & 600 \\
\hline D & 600 \\
\hline E & 600 \\
\hline F & 600 \\
\hline
\end{tabular}

Since the composites did not show any impact of the fillers on the CTI values using solution A of the IEC 60112 method, solution B was used in place of A. This solution leads to more aggressive surface discharges, and it is classified as a more aggressive contaminant than solution A. It consists of high purity anhydrous ammonium chloride of $99.8 \%$ purity was mixed with $0.5 \%$ of by mass of sodium-di-butyl naphthalene sulfonate in de-ionized water, having a conductivity of not greater than $1 \mathrm{mS} / \mathrm{m}$. The other parameters were identical to the conditions used with solution A. The results of CTI with solution B are shown in Table 4.

Table 4 Comparative tracking index of hybrid composites with solution B of IEC-60112 method

\begin{tabular}{|c|c|}
\hline Composite & CTI \\
\hline A & 600 \\
\hline B & 600 \\
\hline C & 600 \\
\hline D & 560 \\
\hline E & 540 \\
\hline F & 520 \\
\hline
\end{tabular}

Thus, with more aggressive contaminants, the effect of semiconducting filler is evident. Though the current magnitudes increase due to the nature of the fillers, the surface suffers erosion of less than $0.1 \mathrm{~mm}$ depth and hence accumulation of contaminant takes place. The unequal distribution of thermal energy results in relatively more thermal degradation and hence CTI values show a decreasing trend.

\section{(ii) Arc Resistance}

The arc resistance is an important surface parameter which helps in the assessment of the capability of the materials to withstand high voltage low current intermittent arcs on the surface. The advantage of this testing procedure is its capability to measure the insulation recovery property, which is lost due to the presence of high voltage low current arcs. The arc resistance of the composites is a measure of the capability of the materials to withstand $12.5 \mathrm{kV}$ arc, with a gradual increase in current over typical $60 \mathrm{~s}$ cycles. It is measured in terms of time and the composites with arc resistance of $420 \mathrm{~s}$ is deemed to be a good polymer for barrier applications. The values of the arc resistance of the composites are shown in Table 5. The table also shows the extent of insulation recovery after the extinction of the arc. It is a measure of the surface degradation the composite undergoes due to the presence of surface arcs of low current magnitudes at $12.5 \mathrm{kV}$. It is observed that the composites are able to recover their surface insulating property to a good extent. It is mainly the thermal capability of the composites imparted by the fillers which help in the retention of the insulating properties.

Table 5 Arc resistance of the hybrid composites

\begin{tabular}{|c|c|c|}
\hline Composite & $\begin{array}{c}\text { Average arc } \\
\text { resistance (s) }\end{array}$ & $\begin{array}{c}\text { Insulation } \\
\text { recovery (\%) }\end{array}$ \\
\hline A & 420 & 90 \\
\hline B & 420 & 95 \\
\hline C & 420 & 95 \\
\hline D & 390 & 90 \\
\hline E & 390 & 95 \\
\hline F & 380 & 95 \\
\hline
\end{tabular}

\section{CONCLUSION}

In this investigation, the dielectric properties of epoxy hybrid composites with different fillers are investigated. Based on the experimental results, the following conclusions are drawn:

(i) The composite with $\mathrm{MoS}_{2}$ hybrid filler (composite-E) shows the highest dielectric constant of 9 at 25, and 11 at 50 and $75^{\circ} \mathrm{C}$.

(ii) The dissipation factor of the individual composites shows minimal variation in the frequency range $20 \mathrm{~Hz}$ to $10 \mathrm{kHz}$, and it starts increasing from $10 \mathrm{kHz}$, and a relatively higher rate of rise in dissipation factor with frequency is observed beyond $1 \mathrm{MHz}$.

(iii) There is a gradual decrease in the impedance of the composites and this trend is characteristic and independent of the fillers used. At higher frequencies from $10 \mathrm{kHz}$ to $10 \mathrm{MHz}$, minimal differences in the impedance value of the composites are observed.

(iv) From the CTI evaluation, it is confirmed that epoxy has a major role in surface tracking and the fillers help to retain this property when solution $\mathrm{A}$ is used. However, under a more aggressive solution, due to the thermal differential arising from the higher thermal conductivity of the semiconducting fillers, there is a decrease in the CTI of composites with semiconducting fillers.

(v) It is observed that the composites possess good resistance to surface arcs and are able to recover their surface insulating property after the extinction of the arc to a good extent.

\section{ACKNOWLEDGMENT}

The first author would like to acknowledge and thank the support and the encouragement received from the Management of N.M.A.M. Institute of Technology, Nitte, Udupi, Karnataka, India and JSS Science and Technology University, Mysuru, Karnataka, India for undertaking this research work. 


\section{REFERENCES}

[1] Abdullah Al Mahmood, Abdul Mobin, Rezwon Morshed, Tasmia Zaman, "Characterization of Glass Fibre Reinforced Polymer Composite Prepared by Hand Layup Method," Amer. J. Biosci. Bioeng., 2017, vol. 5, pp. 8-11.

[2] T P Sathish Kumar, S Satheesh Kumar, J Naveen, "Glass Fiber-Reinforced Polymer Composites - a Review,” J. Reinforced Plastics and Composites, 2014, vol. 33, pp. 1258-1275.

[3] Manju M B, Sai Vignesh, Nikhil K S, Sharaj A P, Madhav Murthy, "Electrical Conductivity Studies of Glass Fiber Reinforced Polymer Composites," Int. Conf. Adv. Mater. Appl., 2018, vol. 5, pp. 3229-3236.

[4] Vijaya Kumar Eesarapu, Saidulu Pagidipalli, V Suresh, G V Ramesh Kumar, "Study and Testing of Glass Fibre Reinforced Plastics," Int. J. Recent Trends in Eng. Res., 2016, vol. 2, pp.115-123.

[5] M. K. Gupta, "Investigations on Properties of Glass Fibre Reinforced Polymer Composite," Amer. J. Polym. Sci. Eng., 2018, vol. 6, pp.31-44.

[6] K. Srinivas, M. S. Bhagyashekar, B.G. Darshan, "Effect of Fillers on Electrical Conductivity of Epoxy Composites," J. Polym. Composites, 2018, vol. 6, pp.25-30.

[7] Waleed A. Hussain, Abdullah A. Hussein, Jabar M. Khalaf, Ali H. Al-Mowali, Abdullwahab A. Sultan, "Dielectric Properties and a.c. Conductivity of Epoxy/Alumina Silicate NGK Composites," Adv. Chem. Eng. Sci., 2015, vol. 5, pp. 282-289.

[8] Anindya Sundar Das, Dipankar Biswas, "Investigation of AC conductivity mechanism and dielectric relaxation of semiconducting neodymium-vanadate nanocomposites: temperature and frequency dependency," Mater. Res. Express, 2019, vol. 6, pp.1-15.

[9] Naresh Chillu, A Jeshurun, R Jayaganthan, R Velmurugan, R Sarathi, "Investigation on dielectric and mechanical properties of epoxy reinforced with glass fiber and nano-silica composites," Mater. Res. Express, 2019, vol. 6, pp.1-21.

[10] Xinfeng Wu, Ying Wang, Liyuan Xie, Jinhong Yu, Fei Liu, Pingkai Jiang, "Thermal and Electrical Properties of Epoxy Composites at High Alumina Loadings and Various Temperatures," Iranian Polym. J., 2013, vol. 22, pp. 61-73.

[11] Z. M. Elimat, M. S. Hamideen, K. I. Schulte, H. Wittich, A. de la Vega, M. Wichmann, S. Buschhorn, "Dielectric properties of epoxy/short carbon fiber composites,” J. Mater. Sci., 2010, vol. 45, pp. 5196-5203.

[12] K. Y. Lau, A. S. Vaughan, G. Chen, I. L. Hosier, A. F. Holt, K. Y. Ching, "On the Space Charge and DC Breakdown Behaviour of Polyethylene/Silica Nanocomposites," IEEE Trans. Dielectr. Electr. Insul., 2014, vol. 21, pp. 340-341.

[13] M. J. Kadhim, A. K. Abdullah, I. A. Al-Ajaj, A. S. Khalil, "Dielectric Properties of Epoxy/ $\mathrm{Al}_{2} \mathrm{O}_{3}$ Nanocomposites,” Int. J. Appl. Innov. Eng. Manage., 2014; vol. 3, pp. 468-477.

[14] Santanu Singha, M. Joy Thomas and Ajit Kulkarni, "Complex Permittivity Characteristics of Epoxy Nanocomposites at Low Frequencies," IEEE Trans. Dielectr. Electr. Insul., 2010, vol.17, pp.1249-1258.
Bommegowda K B was born in India in the year 1985. He received a B.E. degree in Electronics and Communication Engineering from the Visvesvaraya Technological University, Belagavi, Karnataka in 2010 and an M.Tech. degree in Industrial Electronics from Visvesvaraya Technological University, Belagavi, Karnataka, in 2015. He is presently an Assistant Professor in the Department of Electronics \& Communication Engineering, N.M.A.M. Institute of Technology, Udupi, India. His research interest includes nano dielectrics and insulation systems.

N M Renukappa was born in India in the year 1959. He received a Ph.D. from Visvesvaraya Technological University, Belagavi, Karnataka, India in 2007, an M.S. degree from Birla Institute of Technology and Science, Pilani, India in 1996 and a B.E. from the University of Mysore in 1992. He is a Professor in the Department of Electronics \& Communication Engineering at JSS Science \& Technology University, Mysuru, India. His research interest includes nano dielectrics and insulation system, power electronics, nanocomposite and devices.

J Sundara Rajan (M'09-SM'09) was born in India in the year 1957. He received the M.Sc., (Physics), M.Sc., (High Voltage) and Ph.D. (Electrical Engineering). He has 40 years of experience in Electrical insulating materials and systems. He was the former Additional Director at Central Power Research Institute, Bangalore India. He is presently a Research Advisor at Siddaganga Institute of Technology, Tumakuru, Karnataka, India. His present interests in Research includes nano dielectrics, conducting polymers and materials for Electromagnetic shielding. 